Article

\title{
The Effect of Fuel Injection Equipment of Water-In-Diesel Emulsions on Micro-Explosion Behaviour
}

\author{
Mhadi A. Ismael ${ }^{1}$, Morgan R. Heikal ${ }^{1,2}$, A. Rashid A. Aziz ${ }^{1, *}$ and Cyril Crua ${ }^{2}$ (D) \\ 1 Mechanical Engineering Department, Universiti Teknologi Petronas, Seri Iskandar 32610, Malaysia; \\ xmhadosx@yahoo.com (M.A.I.); M.R.Heikal@brighton.ac.uk (M.R.H.) \\ 2 School of Computing Engineering and Mathematics, University of Brighton, Brighton BN2 4GJ, UK; \\ c.crua@brighton.ac.uk \\ * Correspondence: mhadi_g03348@utp.edu.my; Tel.: +60-1126-786-003
}

Received: 14 February 2018; Accepted: 31 March 2018; Published: 25 June 2018

\begin{abstract}
The number and size distributions of the water dispersed phase have a significant effect on both the long-term stability of an emulsion, and the probability of micro-explosions inside an engine. The emulsions are subjected to intense pressure and shear flow in the fuel injection equipment resulting in changes in the number and size distributions of the dispersed phase. These changes, in turn, have significant effects on the micro-explosion behavior of the droplets. To our knowledge, these effects are not known and have not been reported previously. To uncover some of these effects we carried out a comprehensive experimental investigation on an emulsion spray of $10 \%$ water (by volume) in diesel at different injection pressures of 500, 1000 and 1500 bar. A measurement system consisting of a high-speed camera was used to visualize the droplets' micro-explosions and a thermocouple measured the temperature. Our measurements indicated that the emulsion shear in the injector nozzle shifted the emulsion droplet size distribution towards the smaller end resulting in a delay in the onset of micro-explosion. This delay in the onset of the micro-explosion is thought to be due to the decrease in the dispersed water coalescence rate which, in turn, increases the stability of the emulsion. The results also show that this delay in the onset of micro-explosion, and the temperature required for its onset, increased with injection pressure.
\end{abstract}

Keywords: water-in-diesel; injector shearing; micro-explosion; puffing; dispersed water droplet

\section{Introduction}

Diesel is the dominant fuel used in a variety of applications due to its high energy density, high cetane number and low cost. However, its combustion does not meet the current more stringent emission regulations, particularly for nitrogen oxide $\left(\mathrm{NO}_{\mathrm{x}}\right)$ and particulate matter $(\mathrm{PM})$. Different strategies have been used to reduce the emissions, such as particulate filters, exhaust gas recirculation and dual injection [1-4]. However, these strategies are considered unsuitable for retrofitting on existing vehicles due to the complex engine modification requirements. Therefore, interest in studying and improving the properties diesel fuel itself to reduce the exhaust emissions of regulated pollutants is growing.

Strategies involving the use of water in diesel engines offer a way to potentially reduce $\mathrm{NO}_{x}$ emissions and improve the combustion process [5-7]. One such strategy is the use of waterin-diesel emulsions. When a water-in-diesel emulsion is subjected to high temperature, water molecule dissociation can form hydroxyl radicals which help to oxidize the soot thus reducing the emissions [8]. In addition, the combustion process can be improved as a result of secondary 
atomization of the emulsion droplets and hence better air-fuel mixing [9]. In secondary atomization, water-in-diesel droplets break up into smaller droplets, which is believed to be due to puffing and micro-explosions [10]. Micro-explosion refers to the diffusional breakup of droplets due to the volatility difference between the oil (continuous phase) and water (dispersed phase). The explosive boiling of water (micro-explosion) breaks up the emulsion droplets into smaller ones, whilst in puffing some water leaves the droplets in the form of a very fine mist [11,12].

Droplet micro-explosion has been an object of research since 1962 [13]. A considerable amount of literature has been published on the micro-explosion behavior of emulsified fuel droplets [14-18]. The earlier studies demonstrate a strong and consistent association between disruptive burning in emulsions and engine performance and emissions [19-22]. Although water in diesel emulsions is known to reduce $\mathrm{NO}_{\mathrm{x}}$ and $\mathrm{PM}$ simultaneously, it was found that the size of the dispersed phase water droplet had a significant effect on the combustion and emissions behavior of the emulsion. For example it was reported that $\mathrm{NO}$ emissions increased with water droplets of $2.1 \mu \mathrm{m}$ but for larger droplets $(5.5 \mu \mathrm{m}) \mathrm{NO}_{x}$ was reduced by $25 \%$ [23]. It was also found that the engine efficiency increased by up to $20 \%$ with small dispersed droplet sizes $(0.53 \mu \mathrm{m})$ [24]. Yang et al. [21], argued that this was due to an acceleration of the flame propagation in the case of the small dispersed phase water droplets resulting in a shortening of the combustion duration. Overall, these studies provide reasonably consistent evidence of an association between the water dispersed droplet size and engine performance.

Micro-explosion is a very fast process, and hence the Leidenfrost technique is often used to facilitate the observation of the fast evaporation of the droplet [25-28]. Under Leidenfrost conditions, heat transfer by conduction is the dominant mode, and causes a rapid evaporation of the droplet. Kadota et al. [12] used a hot plate to investigate emulsion droplet micro-explosions under Leidenfrost conditions. Khan et al. [29] conducted a series of experiments on water emulsified diesel suspended on a thin-wire thermocouple to study the Leidenfrost effect. They conclusively showed that for micro-explosions to occur, large dispersed phase water droplets with faster coalescence rate must exist. This finding is consistent with that of Kimoto et al. [30] who argued that dispersed phase water droplet sizes larger than $10 \mu \mathrm{m}$ were found to initiate micro-explosions, whereas fine droplets (average diameter 1-2 $\mu \mathrm{m}$ ) did not give rise to micro-explosions. Mura et al. [31] observed a transparency region in the thick emulsion ( 0.19 to $0.33 \mathrm{~mm}$ diameter) due to the evaporation of the dispersed phase, however with a fine dispersed phase, the coalescence did not progress and therefore the temperature required for micro-explosions increased. The optimum dispersed water phase droplet size was found to be about $4.7 \mu \mathrm{m}$ [32].

Recent research suggested that the dispersed phase water droplet size is the dominant factor for micro-explosion occurrence [25]. However, in a spray, the dispersed droplet size distribution is completely different from the sizes in single droplet experiments. The effect of the preparation method of an emulsion, and the fuel pump and injector nozzles used will determine the distribution of both the number and size of the droplets and hence the occurrence of micro-explosion. For example, a homogenizer and mechanical stirrer were used in a previous study [29]. It was observed that all samples of mechanically-stirred emulsions exploded, but no micro-explosion was observed when the emulsion was produced using a homogenizer. It was concluded that in order to control the micro-explosion of emulsified fuels it is essential to control the number and size distributions of the dispersed phase from the injector.

From this point of view, when an emulsion passes through the fuel injection equipment the size distribution of the disbursed phase will change which in turn will have an effect on the onset of micro-explosions. To the authors' best knowledge, this effect has never been investigated.

The current study aims to experimentally investigate the impact of injector nozzle shear on droplet puffing and micro-explosions of water-in-diesel emulsions during Leidenfrost effect conditions. For this purpose, an emulsion with $10 \%$ water concertation by volume was passed through a common rail system. The injection pressure was varied (500, 100 and 1500 bar) and spray samples were investigated to examine the effect of emulsion shear on the droplet size distribution. 


\section{Experimental Method}

The experiments started with water-in-diesel emulsion preparation. The emulsions were characterized at different injection pressures (see Section 2.1). The collected samples from the spray were tested under Leidenfrost conditions and the droplets' micro-explosion behavior was visualized using high-speed video recordings (Section 2.2).

\subsection{Stability and Physical Properties of Emulsified Blends}

The viscosity and density of the neat diesel and emulsions were measured using a Lovis $2000 \mathrm{M}$ viscometer (Anton Paar, Graz, Austria) and an Anton Paar density meter (DMA 4500M). The pendant drop method (OCA 15EC, Data Physics, Graz, Austria) and isoperibol calorimeter (AC-350, Leco, Graz, Austria) were used to measure the surface tension and calorific value. The properties of all fuels tested are shown in Table 1.

A lipophilic surfactant (Span 80) with a hydrophilic-lipophilic balance (HLB) $=4.3$ was used to reduce the interfacial tension between the neat diesel (continue phase) and the distilled water (dispersed phase). To characterize the stability of water-in-diesel emulsion, a mechanical stirrer driven at $1000 \mathrm{rpm}$ was used for the blending of the neat diesel with the surfactant, and the distilled water was added drop by drop. The de-emulsifications of the blends were recorded every $\mathrm{h}$ for the first $6 \mathrm{~h}$, and then at 24-h intervals for 3 days as shown in Figure 1. All samples were stable for the first $4 \mathrm{~h}$, and then exhibited some de-emulsification after $5 \mathrm{~h}$. After 3 days all samples showed complete separation of the emulsions, with the samples that contained the highest concentrations of water resulting in the most significant sedimentation.

Table 1. Properties of neat diesel and water-in-diesel emulsions.

\begin{tabular}{|c|c|c|c|c|}
\hline $\begin{array}{l}\text { Water Content } \\
(\% \text { v } / v)\end{array}$ & $\begin{array}{c}\text { Density at } 25^{\circ} \mathrm{C} \\
\left(\mathrm{kg} / \mathrm{m}^{3}\right)\end{array}$ & $\begin{array}{c}\text { Viscosity at } 40^{\circ} \mathrm{C} \\
\left(\mathrm{mm}^{2} / \mathrm{s}\right)\end{array}$ & $\begin{array}{c}\text { Calorific Value } \\
(\mathrm{MJ} / \mathrm{kg})\end{array}$ & $\begin{array}{c}\text { Surface Tension } \\
\text { @ } 25{ }^{\circ} \mathrm{C} \text { (N.m) }\end{array}$ \\
\hline 0 (neat diesel) & 825 & 3.21 & 43.20 & 27.1 \\
\hline 5 & 848 & 6.12 & 41.89 & 26.1 \\
\hline 10 & 855 & 9.53 & 39.15 & 23.9 \\
\hline 15 & 863 & 11.22 & 36.33 & 21.2 \\
\hline
\end{tabular}

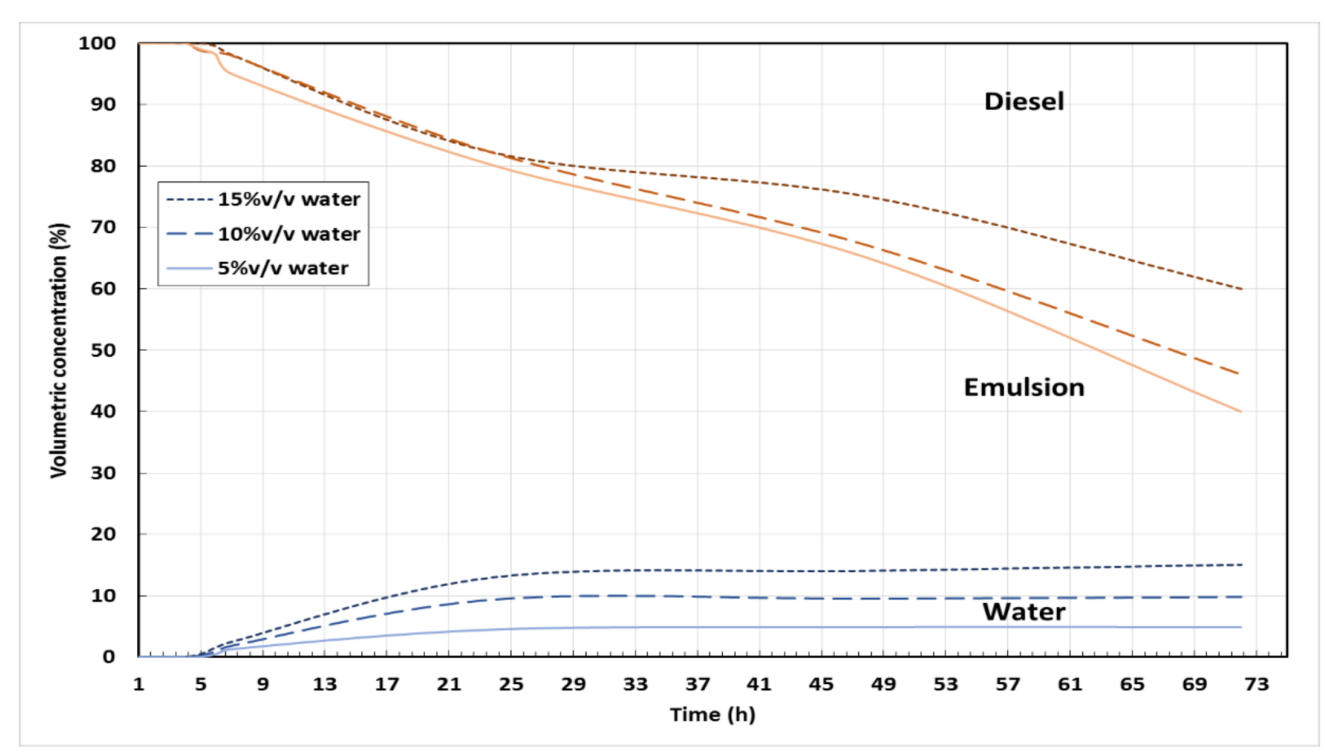

Figure 1. All samples were stable for the first $4 \mathrm{~h}$, and then exhibited some de-emulsification after $5 \mathrm{~h}$. After 3 days all samples showed complete separation of the emulsions, with the samples that contained the highest concentrations of water resulting in the most significant sedimentation. 


\subsection{Fuel Injection System}

A high pressure injector (solenoid valve servo-actuated injector, Denso (Tokyo, Japan), with a 6-hole nozzle and orifice diameter of $0.2 \mathrm{~mm}$ was used to spray the emulsions. The experimental setup (Figure 2) used in the present study is the same as that of the authors' previous work [33]. This injection system provided flexibility in controlling the injection timing, injection duration and the rail pressure. Different injection pressures were used while the injection duration was kept constant at $3 \mathrm{~ms}$ for all the experiments.

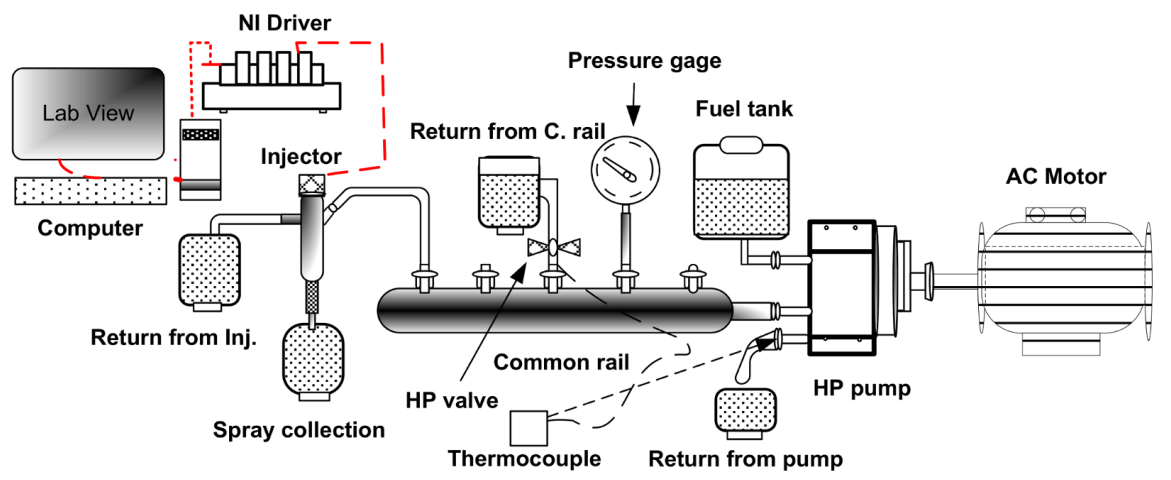

Figure 2. Schematic of the experimental setup.

\subsection{Image acquisition, Processing and Analysis}

The dispersed phase water droplet sizes were measured using a microscope (BX51, Olympus, Model U_LHOOL-3, Tokyo, Japan) with 50× magnification and $10 \mu \mathrm{m}$ depth of field. The sampled blends were deposited on a glass plate for analysis. To avoid cross-contamination of the samples, the glass plate was cleaned using a solvent between each measurement. We focused the microscope half way between the glass/emulsion and emulsion/air interfaces. Since the dispersed droplets within the emulsion tend to agglomerate near the glass/emulsion and emulsion/air interfaces, recording the dispersed droplet distribution near these interfaces could result in a biased measurement. To obtain statically representative droplet size distributions, we scanned 10 different physical locations within each sample of the dispersed droplets using a digital camera. All raw images were then analyzed using a purpose-built MATLAB image processing algorithm to automatically detect the dispersed droplets and measure their sizes [34]. The algorithm successfully detected most droplets, although occasionally some compact agglomerates could not be separated by the watershed transform.

\subsection{Hot Plate Technique}

The experimental set-up used in this study was the same as the previous study by Khan et al. [29]. A high-speed camera (8001-Phantom Miro M310, Wayne, NJ, USA) coupled with high long distance Microscope-K2 (Boulder, Co, USA), a K-type thermocouple and data logger were synchronized to evaluate the micro-explosion event and record the profile of droplet temperature during the event (Figure 3). The camera triggering was set when the thermocouple temperature reached $150{ }^{\circ} \mathrm{C}$ for all emulsion samples. A controlled hot plate was maintained at $500^{\circ} \mathrm{C}$ before dropping the droplet using a syringe with an internal needle diameter of $0.3 \mathrm{~mm}$. The droplet was suspended above the hot plate onto the end point of the thermocouple wire $(0.03 \mathrm{~mm}$ diameter with bead of $0.08 \mathrm{~mm})$ and the gap between the end of thermocouple and hot plate was kept at $2 \mathrm{~mm}$ using a feeler gauge. To ascertain the thermocouple reading, we immersed two thermocouples into hot water at 10 different temperatures. To avoid the heat transfer to the needle tip which may affect the droplet before it is dispensed, the droplet was suspended manually after the thermocouple recorded the required temperature, and the needle promptly retracted. 
A direct visualization system was used to record the event. A Multi LED (LT-V8-15 Tokyo, Japan) was used as the source of illumination in the same direction as the camera. The image acquisition rate was set at $500 \mathrm{fps}$ with a resolution of $1280 \times 800$ pixels and exposure $300 \mu$ s throughout all the experiment. The image sequences of the emulsion droplet, as well as the temperature history, were recorded.

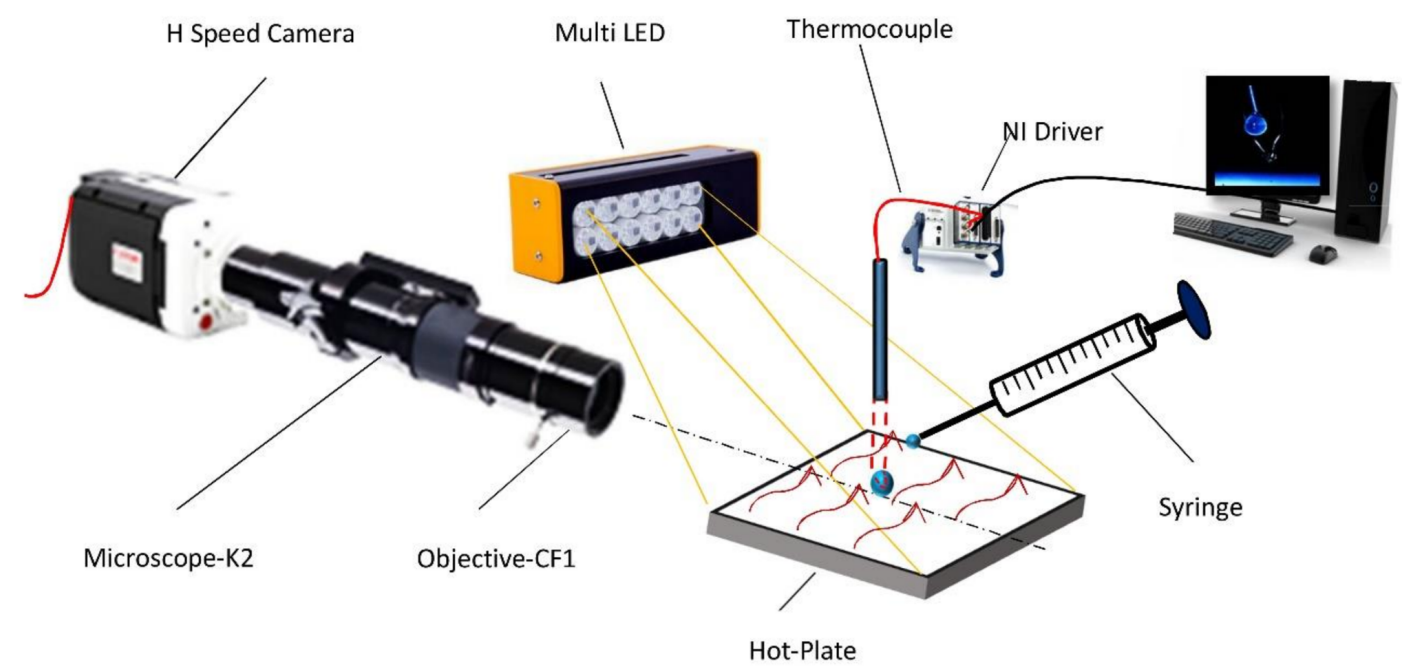

Figure 3. Experimental setup for the visualization technique.

\section{Results and Discussion}

In this section, it will be demonstrated that the injector nozzle orifice has an effect on the size of the emulsion dispersed phase water droplet, due to injector shearing and pressure (Section 3.1). The water concentration decreased or evaporated during the spray, thereby affecting the micro-explosion process (Section 3.2). Significant observations were recorded showing that the droplet micro-explosion was delayed with the increasing injection pressures (Section 3.3).

\subsection{The Effect of Injector Shearing on Droplet Size Distribution}

To ascertain whether the injector nozzle had an effect on the emulsion, we measured the dispersed phase water droplets size distributions (Figure 4) before the injection system in the fuel tank (A) and after the injector for injection pressures of 500 bar (B), 1000 bar (C) and 1500 bar (D). It can be seen that the size and number of the dispersed water droplets were affected significantly by the injector nozzle, with the water phase droplet size and number increasing with the increase in injection pressure. Indeed, in the injector nozzle the emulsion was subjected to an intense turbulent and shear flow fields, causing the break-up of the dispersed phase into small droplets. This result is in agreement with droplet breakage of emulsion using a homogenizer [15]. The mean droplet diameters for the samples A, B, C and D were 5.58, 2.57, 1.2 and $0.7 \mu \mathrm{m}$ respectively. These observations support the hypothesis that the emulsion in the fuel tank will not represent the actual fuel spray. Therefore, this reduction in size distribution could significantly reduce the propensity for the emulsion to explode while mixing inside the combustion chamber.

On the other hand, concerning the water concentration after the spray, we measured the density of the samples, and then used a mixing model to compute the water concentration for each sample. Interestingly, the water concentration was found to decrease with the increase of injection pressure. For example, with the increase of injection pressure i.e., 500, 1000 and 1500 bar, the water concentrations were reduced to $9,8.3$ and $7.5 \%$ respectively. This result indicated some of the water was lost or evaporated during the injection. 


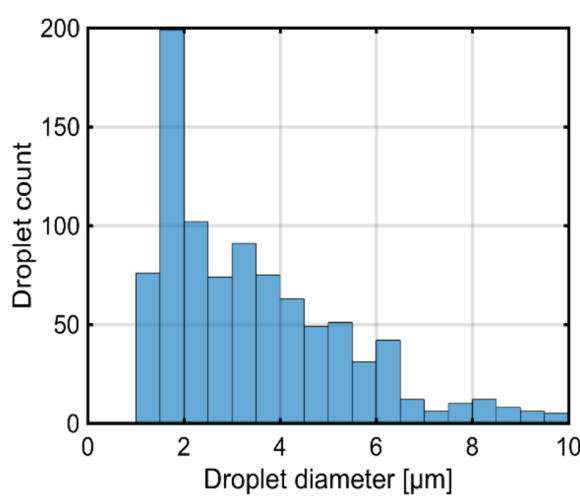

(A)

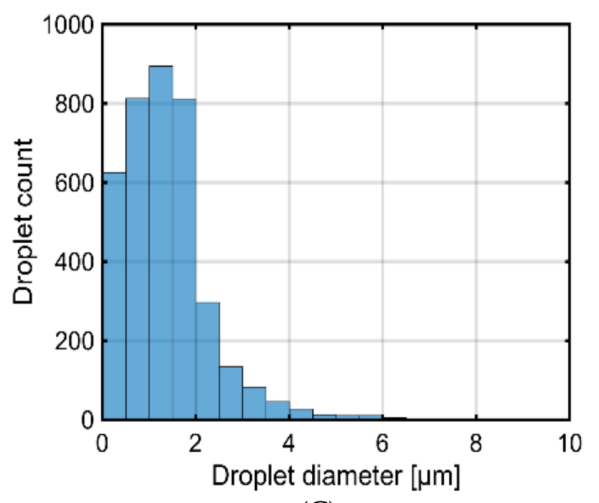

(C)

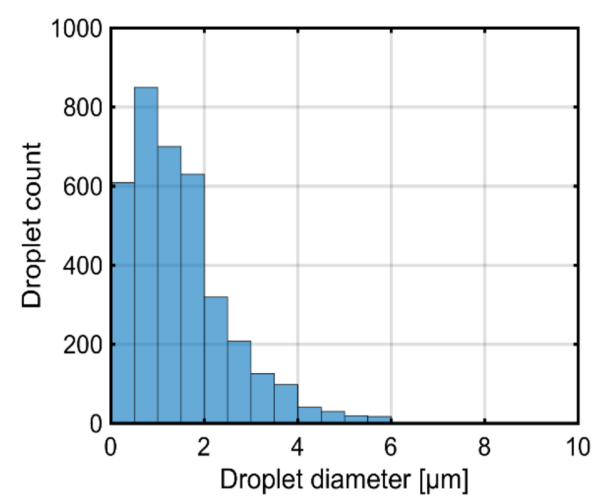

(B)

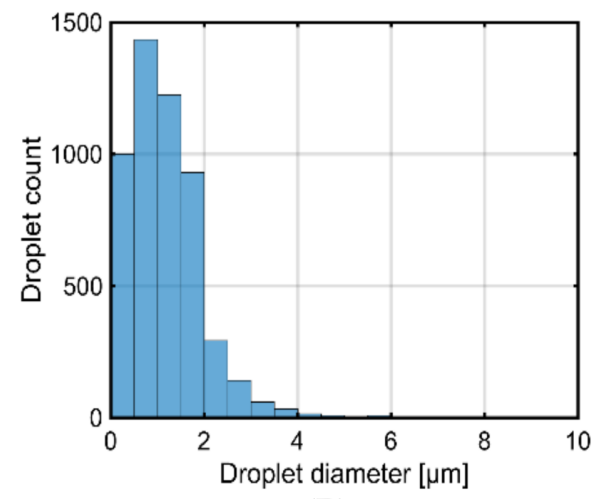

(D)

Figure 4. Represent the histogram for the emulsions of $10 \%$ water content at: (A) fuel in tank and (B),

(C,D) emulsions collected from the spray at 500, 1000 and 1500 bar respectively.

\subsection{Micro-Explosion Phenomenon}

In order to investigate the micro-explosion phenomenon, the droplets were suspended onto a thermocouple under Leidenfrost conditions with the hot plate temperature controlled at $500{ }^{\circ} \mathrm{C}$. The camera and data logger were triggered when the thermocouple temperature reached $150{ }^{\circ} \mathrm{C}$. It was thought that the presence of thermocouple during the droplet boiling may generate heterogeneous nucleation and hence influence the onset of micro-explosion. However, previous studies found that the presence of the thermocouple had no predominant effect on the initiation of micro-explosion $[15,27,35]$. We, therefore, did not consider the presence of the thermocouple in the micro-explosion behavior. To obtain statically representative droplet micro-explosion time and temperature, we visualized 10 times within each sample of the dispersed droplets. The percentage of micro-explosion occur for the sample in fuel tank was $90 \%$ and $70 \%$ for the other samples.

Figure 5 , shows image sequences of a droplet for the evolution of micro-explosion phenomena of emulsion made with $10 \%$ water concentration by volume. A sample from the fuel tank (A) was first tested to establish a base line. As can be seen from the images, initially the droplet appeared turbid (milky white) as expected for a macro-emulsion due to reflection of light and the presence of micrometric dispersed water droplets. Puffing was observed at $t=0.272 \mathrm{~s}$ and continued with coalescence and phase separation. The droplet transparency increase by water boiling and finally micro-explosion occurred at about $1.680 \mathrm{~s}$. In fact, the mechanisms of micro-explosion such as aggregation, coalescence, evaporation, transparency and puffing during heating of the droplet are common stages of the phenomena [25,31,36-38]. The temperature profile of case A is shown in Figure 6. The dots represent the temperature of a single droplet at each stage. It can be seen that the thermocouple temperature dropped to $117^{\circ} \mathrm{C}$ initially, due to direct contact with the droplet, and stabilized while evaporation took place at the periphery of the droplet. Then, the droplet evaporation time decreased 
as the temperature of the surface increased. After this time (at $t=1.050 \mathrm{~s}$ ), the temperature of the droplet increased to $133^{\circ} \mathrm{C}$, and vapor bubbles formed at the top of the droplet while water droplets coalesced with an increase of temperature $\left(158^{\circ} \mathrm{C}\right)$, at this moment the micro-explosion occurred. The thermocouple temperature continued increasing until it became stable at $\left(164{ }^{\circ} \mathrm{C}\right)$.

A

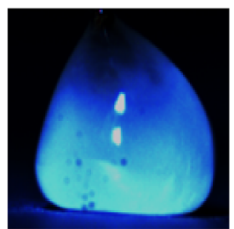

$\mathrm{t}=0.00 \mathrm{~s}$

B

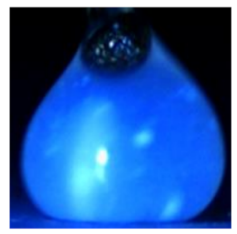

$\mathrm{t}=0.00 \mathrm{~s}$

C

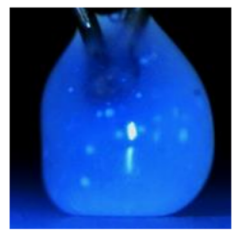

$t=0.00 s$

D

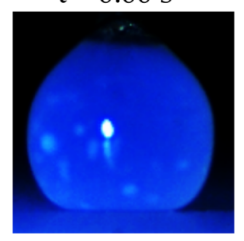

$\mathrm{T}=0.002 \mathrm{~s}$

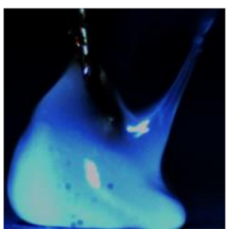

$t=0.272 \mathrm{~s}$

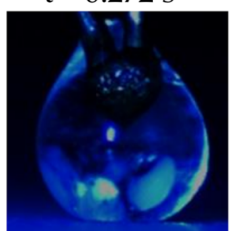

$\mathrm{t}=1.121 \mathrm{~s}$

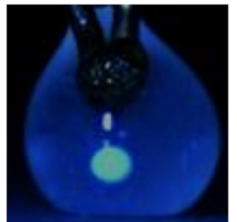

$\mathrm{t}=1.151 \mathrm{~s}$

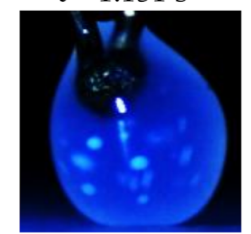

$t=0.034 \mathrm{~s}$

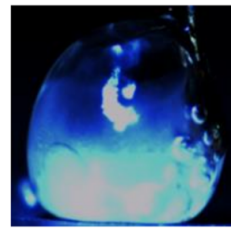

$\mathrm{t}=0.689 \mathrm{~s}$

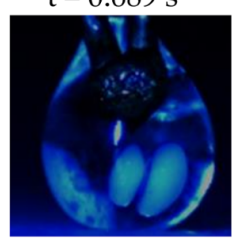

$\mathrm{t}=1.589 \mathrm{~s}$

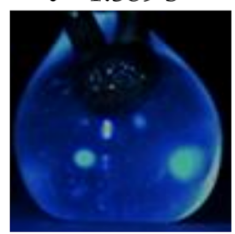

$t=1.292 \mathrm{~s}$

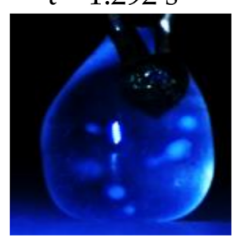

$t=0.248 \mathrm{~s}$

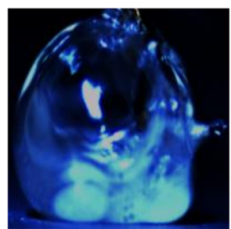

$\mathrm{t}=1.050 \mathrm{~s}$

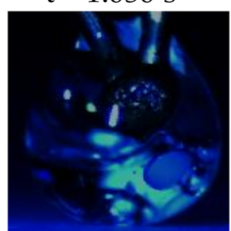

$t=1.850 \mathrm{~s}$

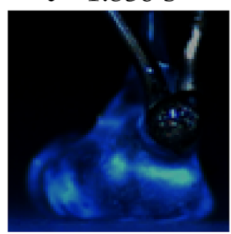

$\mathrm{t}=2.073 \mathrm{~s}$

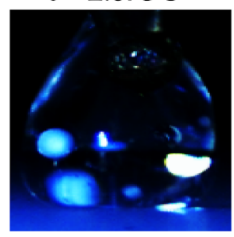

$\mathrm{t}=1.308 \mathrm{~s}$

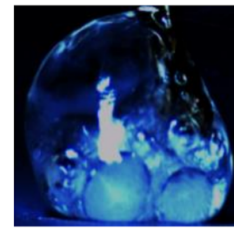

$\mathrm{t}=1.440 \mathrm{~s}$

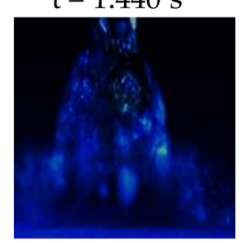

$t=2.01 \mathrm{~s}$

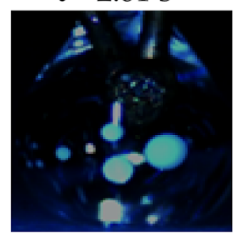

$t=2.178 \mathrm{~s}$

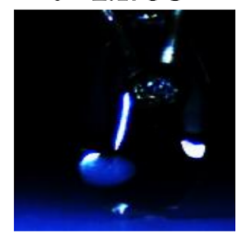

$t=2.83 \mathrm{~s}$

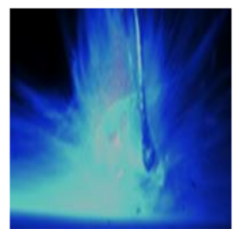

$\mathrm{t}=1.680 \mathrm{~s}$

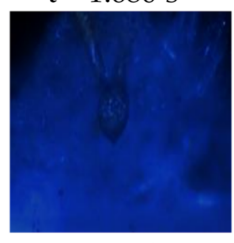

$\mathrm{t}=2.256 \mathrm{~s}$

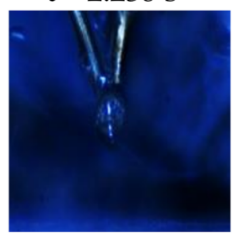

$\mathrm{t}=2.818 \mathrm{~s}$

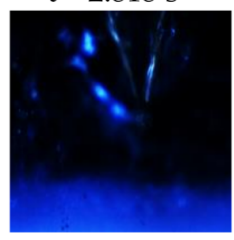

$t=3.52 \mathrm{~s}$

Figure 5. Micro-explosion behavior during Leidenfrost of cases A, B, C and D.

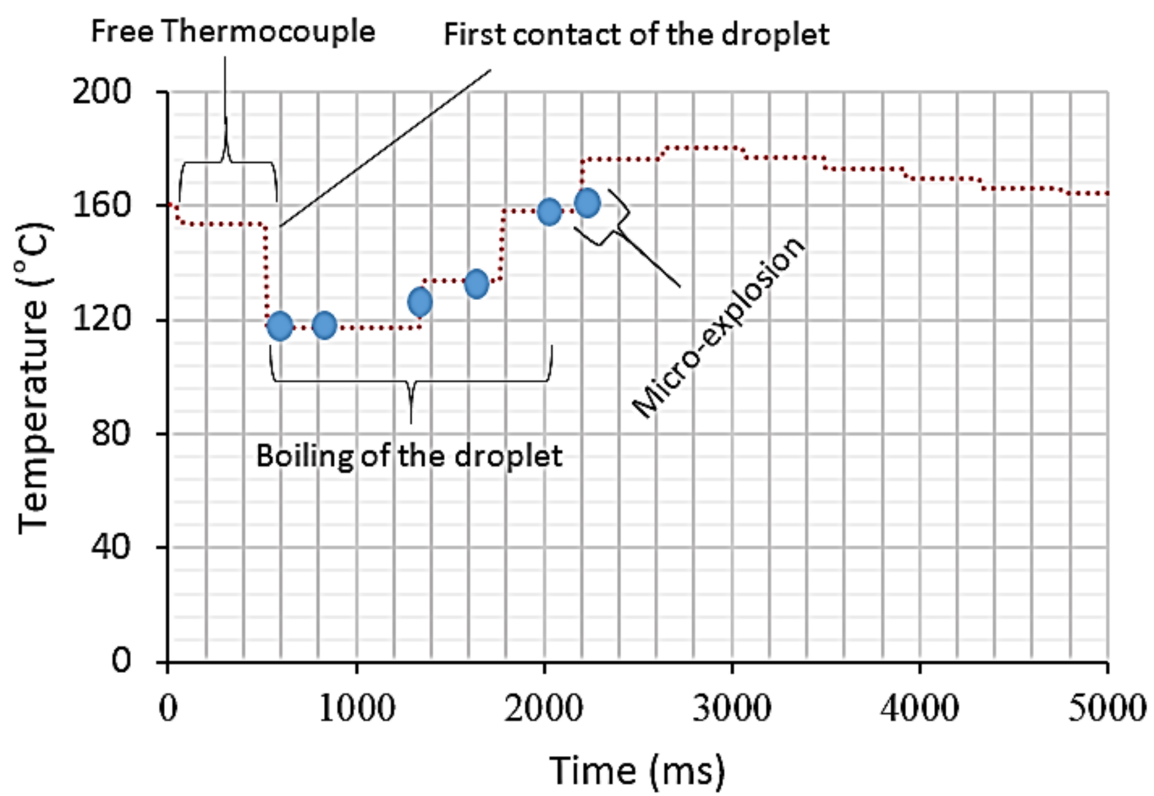

Figure 6. Temperature evolution of case A. 
The same emulsion as sample A was then pumped through the nozzle at injection pressures of 500, 1000 and 1500 bar, and samples B, C and D, respectively, were collected after injection in order to examine the effect of the injection system on the micro-explosion behavior. The samples were tested shortly (in about $15 \mathrm{~min}$ ) after they were collected in order to avoid coalescence of the dispersed water. As can be seen from Figure 5, all the emulsion samples showed more transparency compared to sample A. The semi-translucent appearance increased with the smaller dispersed water droplet sizes resulting from the increase in the injection pressure. This change in appearance confirms that a significant part of the macro-emulsion shifted towards a nano-emulsion as a result of the injection process. For case A, puffing occurred eight times but was only observed three and two times for cases B and C, respectively. In case $\mathrm{D}$, puffing occurred only once. This can be attributed to the water droplet distribution in the spray. At 1500 bar injection pressure the water droplets were of the order of $0.7 \mu \mathrm{m}$, which was too small for coalescence resulting in a low rate of evaporation and puffing. Another explanation for these observations can be attributed to the reduction of water concentration after the injector nozzle. These findings are consistent with the findings of Khan et al. [29], who found that large dispersed droplet sizes enhanced the puffing and reduced the time for the onset of micro-explosion, and those of Abu-Zaid [39] who reported that the evaporation time of emulsions is water dependent, decreasing with the increase of water concentration.

The evolution of micro-explosion of case D took a comparatively longer time than B and C. Qualitatively, a similar behavior to emulsion $C$ was observed, but the whole phenomena took $3.52 \mathrm{~s}$ as shown in Figure 5D, compared to $2.818 \mathrm{~s}$ for emulsion $\mathrm{C}$ and $2.256 \mathrm{~s}$ for emulsion B. These results can be attributed to the mechanism of micro-explosion [36]. It can be seen that the dispersed phase droplets coalescence rate decreases with the increase of injection pressure leading to a longer time for micro-explosion to take place (Figure 5). This is in agreement with Mohan and Narsimhan [40], who showed that the coalescence rate for small droplets is low due to these droplets being thermodynamically stable.

Interestingly, the emulsions in cases $\mathrm{C}$ and $\mathrm{D}$ became completely translucent before they exploded. This was thought to be due to the evaporation of the fine dispersed water droplets, however some droplets coalesced and generated a few large droplets triggering micro-explosion. These results provide further support for the hypothesis that the strength of micro-explosion results from the evaporation of a large number of fine dispersed phase droplets rather than one or a few large dispersed droplets [15].

\subsection{Temporal Temperature Profiles}

The plot in Figure 7 represents the temperature evolution of the droplets corresponding to the images in Figure 5B-D. The initial temperatures of the droplets were 117,122 and $123^{\circ} \mathrm{C}$ for cases B, C and $\mathrm{D}$, respectively. The temperature of micro-explosion for case $\mathrm{B}$ were $180^{\circ} \mathrm{C}(\mathrm{t}=2.25 \mathrm{~s})$ and $196{ }^{\circ} \mathrm{C}$ $(t=2.81 \mathrm{~s})$ for case $\mathrm{C}$. While in case $\mathrm{D}$ it was $205^{\circ} \mathrm{C}(\mathrm{t}=3.52 \mathrm{~s})$. It can be seen that the temperature required for the onset of micro-explosion increased with the decrease of the size of the dispersed water phase droplets. These results are consistent with those of Mura et al. [31], who found that the temperature for micro-explosion increased to $200^{\circ} \mathrm{C}$ for fine dispersed phase water droplets indicating the state of metastability of water. In the next section we will show that the coalescence of the dispersed phase water droplet size and the parent droplet size changed during the heating time. 


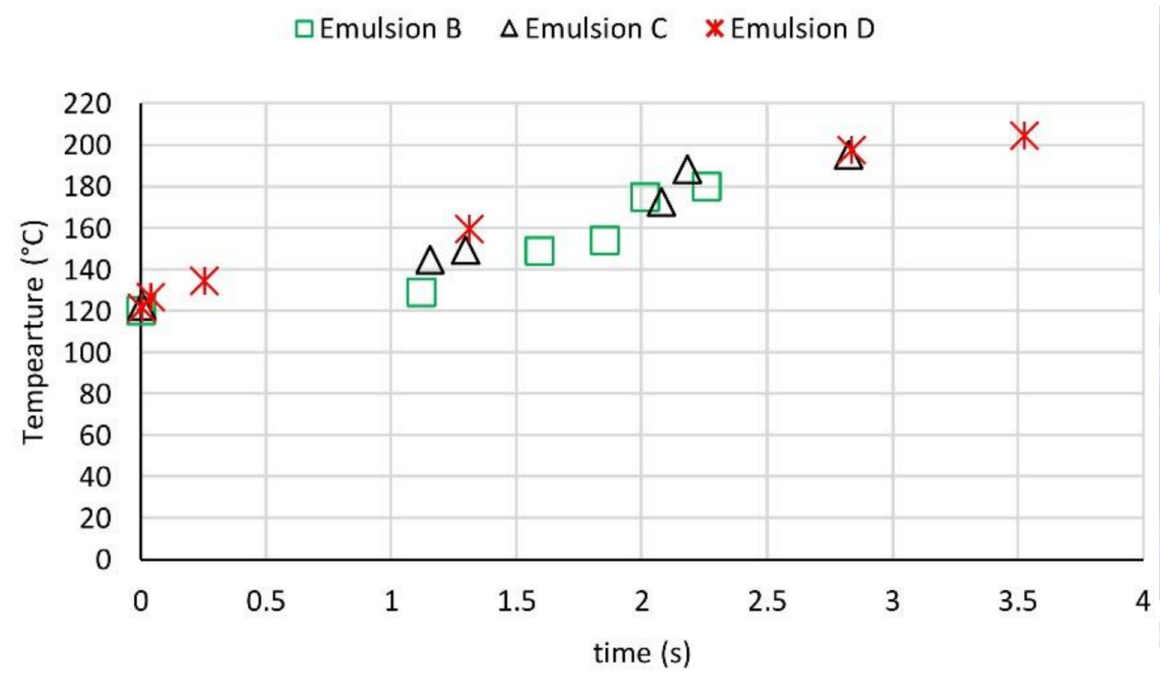

Figure 7. Temperature profiles of case B, C and D.

\subsection{The Effect of Dispersed Water Droplet Coalescence on Micro-Explosion Behavior}

It is generally accepted that the strength of micro-explosions results from the combined evaporation of a large number of fine dispersed phase water droplets [15]. It is, therefore, important to understand the water sub-droplet coalescence and evaporation processes and factors influencing them. We used an image processing system to identify the droplet edges, and thereby to ascertain whether the emulsion's water droplets evaporated or coalesced. Figure 8 shows the droplet heating behavior of case $\mathrm{D}$ (raw image) and $\mathrm{d}$ (after edge detection). The water, water vapor, diesel and the light reflection are distinguished by darker gray (green) and lighter green for water, (lighter blue) for the water vapor, (black) for diesel and darker gray (red) and (yellow) for light reflection. The images reveal that with the increase in the droplet temperature, the water boiling increased and consequently, the sub-droplet oscillated strongly and their shapes changed accordingly. In fact, the interfacial tension between the diesel and water phases is temperature dependent [41]. As a result, all the dispersed phase water droplets (average droplet area $0.005 \mathrm{~mm}^{2}$ at $\mathrm{t}=0.034 \mathrm{~s}$ ) coalesced into two large droplets $(0.020$ and $0.034 \mathrm{~mm}^{2}$ at $\mathrm{t}=1.38 \mathrm{~s}$ ) as shown in the magnified images (Figure 8). After this time, the droplets tend to stabilize on the bottom of the parent droplet, while the water boiled. It can be seen from the magnified images at $\mathrm{t}=1.79 \mathrm{~s}$ to $2.83 \mathrm{~s}$, the water vapor (blue color) increased as the time elapsed, and their area increased accordingly (from $0.025 \mathrm{~mm}^{2}$ to $0.043 \mathrm{~mm}^{2}$ ). After this moment, the droplet stabilized on the bottom of the parent droplet $\left(0.029 \mathrm{~mm}^{2}\right)$, and then micro-explosion occurred at $\mathrm{t}=3.52 \mathrm{~s}$.

These findings indicate that very small dispersed water droplets coalesced to generate a trigger point for micro-explosion, however some of the fine droplets evaporated to form bubbles. These bubbles form at a deeper location inside the diesel phase [36].

The sub-droplet penetration direction is considered key to determine the parent droplet breakup outcome [36]. In summary, in fine dispersed water droplets, the micro-explosion time depended on the explosive boiling of multiple water sub-droplet coalescing into a large droplet.

To further understand the effect of bubble forms on the droplet diameter expansion, we measured the parent droplet size. Figure 9 shows the change in the droplet diameter with respect to time (in accordance with images obtained in Figure 8) of case D. It can be seen that droplet diameter increased initially from $t=0.002$ to $t=1.3 \mathrm{~s}$. This was due to the transient heating causing the droplet to expand by the evaporation of the dispersed phase being greater than the parent droplet shrinkage caused by its evaporation at the surface. After this stage, the dispersed phase water droplets coalesced rather than evaporated, and thus the parent droplet size decreased due to evaporation. 
D
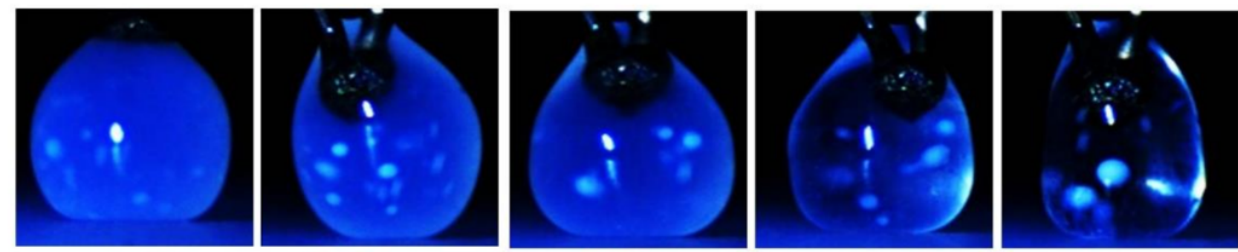

d
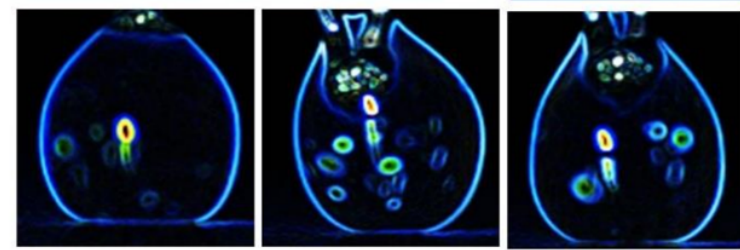

$\mathrm{t}=0.002 \mathrm{~s}$

$\mathrm{t}=0.034 \mathrm{~s}$

$\mathrm{t}=0.248 \mathrm{~s}$
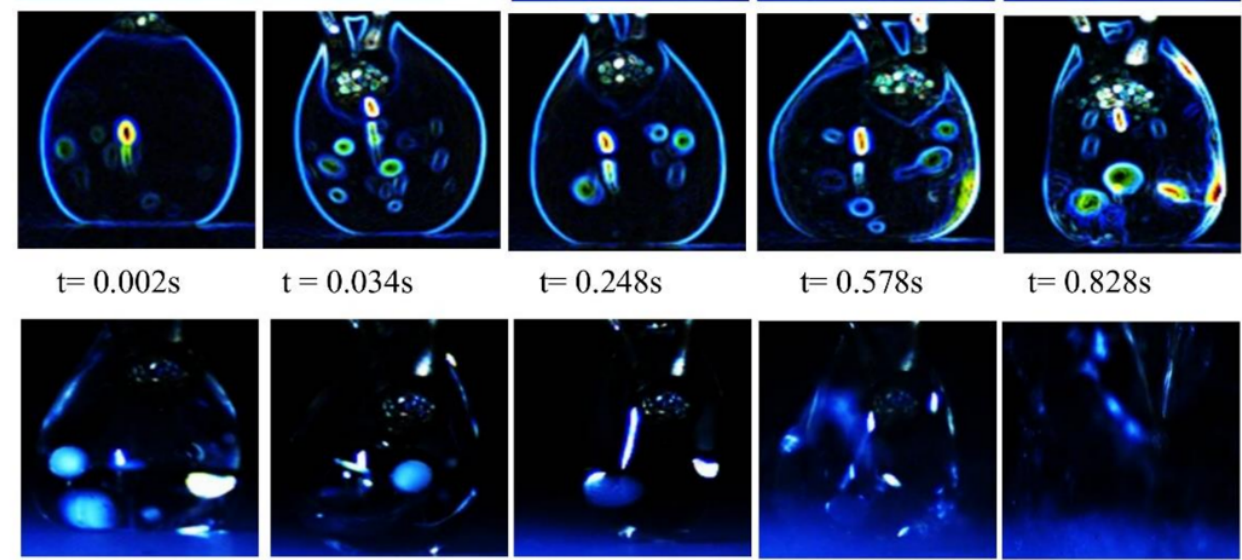

$\mathrm{t}=0.578 \mathrm{~s}$

$\mathrm{t}=0.828 \mathrm{~s}$
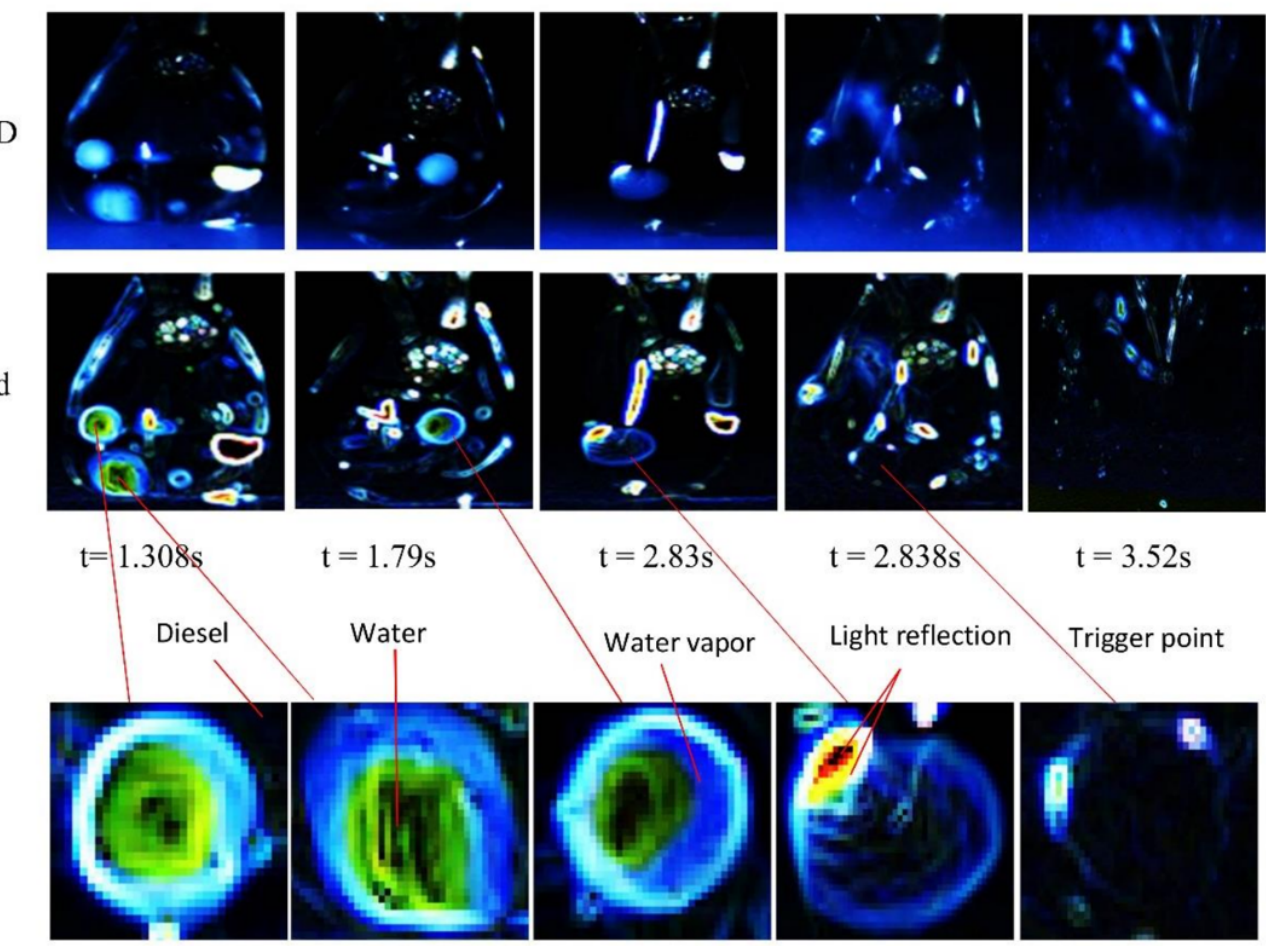

$\mathrm{t}=1.79 \mathrm{~s}$

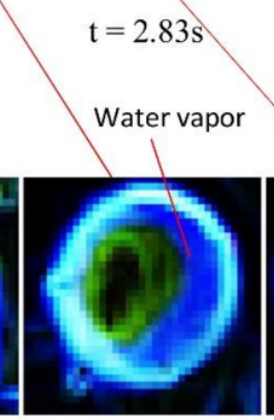

$0.025 \mathrm{~mm}^{2}$

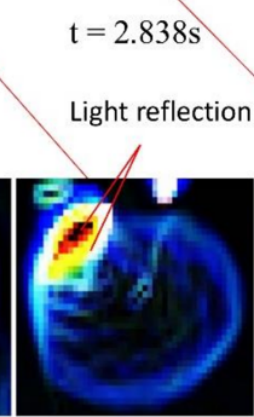

$0.043 \mathrm{~mm}^{2}$

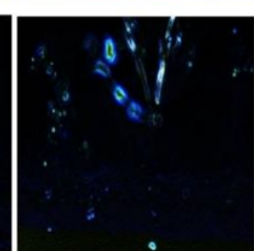

$\mathrm{t}=3.52 \mathrm{~s}$

Trigger point

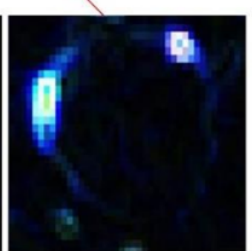

$0.029 \mathrm{~mm}^{2}$

Figure 8. Droplet heating behavior during of emulsion: D (raw image) and d (processed image).

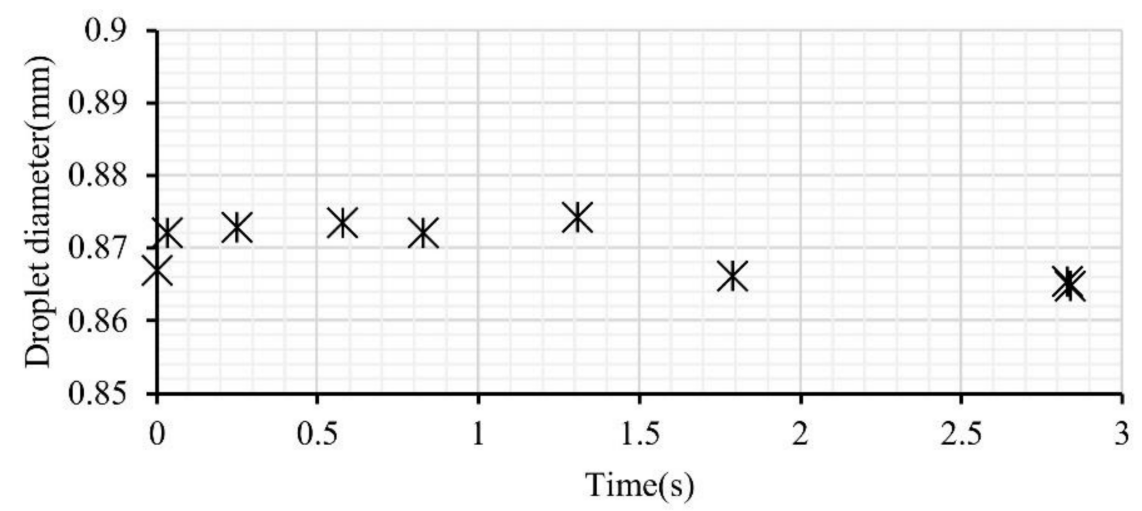

Figure 9. Droplet diameter versus time for sample D. 


\section{Conclusions}

The effect of the injection system on the dispersed phase and micro-explosion phenomena was investigated. An emulsion of $(10 \% v / v)$ water-in-diesel at different injection pressures $(500,1000$ and 1500 bar) was tested under Leidenfrost conditions. Our measurements provide new evidence of the effect of injector nozzle on micro-explosions. Significant findings from this study include:

(1) The dispersed droplet sizes reduce significantly after the emulsion is injected through the nozzle's orifices, and some of the water is lost through evaporation during the injection.

(2) Micro-explosions were delayed as a result of the shear in the injector nozzle. This was found to be the result of a shift of the emulsion towards a nano-emulsion, leading to the deceleration of the coalescence rate which, in turn, increased the stability of the emulsion.

(3) For fine dispersed water droplets, the micro-explosion time depends on the explosive boiling of multiple water sub-droplet coalescence into larger droplet.

(4) The temperature of micro-explosion increases with injection pressure.

As a result of this study, we suggest that differences in injection pressures have a significant effect on the micro-explosion of emulsified fuels. Further research is needed to assess the micro-explosion behavior of emulsified fuels under real engine conditions taking into account the effect of fuel shear in the fuel injection equipment.

Acknowledgments: The authors would like to acknowledge the support given by the Universiti Teknologi PETRONAS to the Centre for Automotive Research and Electric Mobility in performing this research. This work was supported by the Malaysia's Grants PRGS (Ref: PRGS/1/2017/TK07/UTP/01/1)) and FRGS (Ref: FRGS/1/2017/TK10/UTP/01/2).

Author Contributions: The work was supervised by Morgan R. Heikal, A. Rashid A. Aziz and Cyril Crua. The experiments and data analysis were carried out by Mhadi A. Ismael.

Conflicts of Interest: The authors declare no conflict of interest.

\section{References}

1. Sazhin, S.; Crua, C.; Kennaird, D.; Heikal, M. The initial stage of fuel spray penetration. Fuel 2003, 82, 875-885. [CrossRef]

2. Raju, V.R.K.; Rao, S.S. Effect of Fuel Injection Pressure and Spray Cone Angle in DI Diesel Engine Using CONVERGETM CFD Code. Procedia Eng. 2015, 127, 295-300.

3. Yu, X.; Zuo, X.; Wu, H.; Du, Y.; Sun, Y.; Wang, Y. Study on Combustion and Emission Characteristics of a Combined Injection Engine with Hydrogen Direct Injection. Energy Fuels 2017, 31, 5554-5560. [CrossRef]

4. Yang, S.; Moon, H.; Lee, C. A Study of Spill Control Characteristics of JP-8 and Conventional Diesel Fuel with a Common Rail Direct Injection System. Energies 2017, 10, 2104. [CrossRef]

5. Kadota, T.; Yamasaki, H. Recent advances in the combustion of water fuel emulsion. Prog. Energy Combust. Sci. 2002, 28, 385-404. [CrossRef]

6. Ithnin, A.M.; Noge, H.; Kadir, H.A.; Jazair, W. An overview of utilizing water-in-diesel emulsion fuel in diesel engine and its potential research study. J. Energy Inst. 2014, 87, 273-288. [CrossRef]

7. Feng, L.; Du, B.; Tian, J.; Long, W.; Tang, B. Combustion performance and emission characteristics of a diesel engine using a water-emulsified heavy fuel oil and light diesel blend. Energies 2015, 8, 13628-13640. [CrossRef]

8. Lif, A.; Holmberg, K. Water-in-diesel emulsions and related systems. Adv. Colloid Interface Sci. 2006, 123-126, 231-239. [CrossRef] [PubMed]

9. Zhang, X.; Li, T.; Ma, P.; Wang, B. Spray Combustion Characteristics and Soot Emission Reduction of Hydrous Ethanol Diesel Emulsion Fuel Using Color-Ratio Pyrometry. Energies 2017, 10, 2062. [CrossRef]

10. Saad, M.A. Evaporation and Combustion of Single Fuel Deoplet in a Hot Atmosphere; University of Michigan: Ann Arbor, MI, USA, 1956.

11. Law, C.K.; Lee, C.H.; Srinivasan, N. Combustion characteristics of water-in-oil emulsion droplets. Combust. Flame 1980, 37, 125-143. [CrossRef] 
12. Kadota, T.; Tanaka, H.; Segawa, D.; Nakaya, S.; Yamasaki, H. Microexplosion of an emulsion droplet during Leidenfrost burning. Proc. Combust. Inst. 2007, 31, 2125-2131. [CrossRef]

13. Ivanove, V.M.; Nefedov, P.I. Experimental investigation of ths combustion process of natural and emulsified liquid fuels. Natl. Aeronaut. Space Adm. Natl. Sci. Found. 1965, 19, 35-45.

14. Avulapati, M.M.; Ganippa, L.C.; Xia, J.; Megaritis, A. Puffing and micro-explosion of diesel-biodiesel-ethanol blends. Fuel 2016, 166, 59-66. [CrossRef]

15. Califano, V.; Calabria, R.; Massoli, P. Experimental evaluation of the effect of emulsion stability on micro-explosion phenomena for water-in-oil emulsions. Fuel 2014, 117, 87-94. [CrossRef]

16. Fu, W.B.; Hou, L.Y.; Wang, L.; Ma, F.H. A unified model for the micro-explosion of emulsified droplets of oil and water. Fuel Process. Technol. 2002, 79, 107-119. [CrossRef]

17. Girin, O.G. Dynamics of Secondary Breakup of Emulsified Fuel Drop. In Proceedings of the 25th ICDERS, Leeds, UK, 2-7 August 2015; pp. 1-6.

18. Jeong, I.; Lee, K.-H.; Kim, J. Characteristics of auto-ignition and micro-explosion behavior of a single droplet of water-in-fuel. J. Mech. Sci. Technol. 2008, 22, 148-156. [CrossRef]

19. Park, S.; Woo, S.; Kim, H.; Lee, K. The characteristic of spray using diesel water emulsified fuel in a diesel engine. Appl. Energy 2016, 176, 209-220. [CrossRef]

20. Arabaci, E.; Içingür, Y.; Solmaz, H.; Uyumaz, A.; Yilmaz, E. Experimental investigation of the effects of direct water injection parameters on engine performance in a six-stroke engine. Energy Convers. Manag. 2015, 98, 89-97. [CrossRef]

21. Yang, W.M.; An, H.; Chou, S.K.; Chua, K.J.; Mohan, B.; Sivasankaralingam, V.; Raman, V.; Maghbouli, A.; $\mathrm{Li}, \mathrm{J}$. Impact of emulsion fuel with nano-organic additives on the performance of diesel engine. Appl. Energy 2013, 112, 1206-1212. [CrossRef]

22. Bedford, F.; Rutland, C.; Dittrich, P.; Wirbeleit, F. Effects of Direct Water Injection on di Diesel Engine Combustion; SAE Paper 01-2938; SAE: Warrendale, PA, USA, 2000.

23. Lin, C.Y.; Chen, L.W. Comparison of fuel properties and emission characteristics of two- and three-phase emulsions prepared by ultrasonically vibrating and mechanically homogenizing emulsification methods. Fuel 2008, 87, 2154-2161. [CrossRef]

24. Attia, A.M.A.; Kulchitskiy, A.R. Influence of the structure of water-in-fuel emulsion on diesel engine performance. Fuel 2014, 116, 703-708. [CrossRef]

25. Khan, M.Y.; Karim, Z.A.A.; Aziz, A.R.A.; Morgan, R.; Crua, C. Puffing and Microexplosion Behavior of Water in Pure Diesel Emulsion Droplets During Leidenfrost Effect. Combust. Sci. Technol. 2017, 189, 1186-1197. [CrossRef]

26. Volkov, R.S.; Kuznetsov, G.V.; Strizhak, P.A. Influence of droplet concentration on evaporation in a high-temperature gas. Int. J. Heat Mass Transf. 2016, 96, 20-28. [CrossRef]

27. Morozumi, Y.; Saito, Y. Effect of physical properties on microexplosion occurrence in water-in-oil emulsion droplets. Energy Fuels 2010, 24, 1854-1859. [CrossRef]

28. Liu, Z.; Hu, X.; He, Z.; Wu, J. Experimental study on the combustion and microexplosion of freely falling gelled unsymmetrical dimethylhydrazine (UDMH) fuel droplets. Energies 2012, 5, 3126-3136. [CrossRef]

29. Khan, M.Y.; Karim, Z.A.A.; Aziz, A.R.A.; Tan, I.M. Experimental Investigation of Microexplosion Occurrence in Water in Diesel Emulsion Droplets during the Leidenfrost Effec. Energy Fuels 2014, 28, 7079-7084. [CrossRef]

30. Kimoto, Y.; Owashi, K.; Omae, Y. The vaporizing behavior of the fuel droplet of water-in-oil emulsion on the hot surface. Bull. JSME 1986, 258, 4247-4255. [CrossRef]

31. Mura, E.; Massoli, P.; Josset, C.; Loubar, K.; Bellettre, J. Study of the micro-explosion temperature of water in oil emulsion droplets during the Leidenfrost effect. Exp. Therm. Fluid Sci. 2012, 43, 63-70. [CrossRef]

32. Mura, E.; Josset, C.; Loubar, K.; Huchet, G.; Bellettre, J. Effect of dispersed water droplet size in microexplosion phenomenon for water in oil emulsion. At. Sprays 2010, 20, 791-799. [CrossRef]

33. Ismael, M.A.; Heikal, M.R.; Baharom, M.B. Spray characteristics of a diesel-cng dual fuel jet using the schlieren imaging technique. Int. J. Mater. Mech. Manuf. 2015, 3, 145-151. [CrossRef]

34. Otsu, N. A threshold selection method from gray-level histograms. IEEE Trans. Syst. Man Cybern. 1979, 9, 62-66. [CrossRef]

35. Mura, E.; Calabria, R.; Califano, V.; Massoli, P.; Bellettre, J. Emulsion droplet micro-explosion: Analysis of two experimental approaches. Exp. Therm. Fluid Sci. 2014, 56, 69-74. [CrossRef] 
36. Shinjo, J.; Xia, J.; Ganippa, L.C.; Megaritis, A. Physics of puffing and microexplosion of emulsion fuel droplets. Phys. Fluids 2014, 26, 103302. [CrossRef]

37. Dittmann, P.; Dörksen, H.; Steiding, D.; Kremer, F. Influence of Micro Emulsions on Diesel Engine Combustion. MTZ Worldw. 2015, 76, 38-44. [CrossRef]

38. Tarlet, D.; Bellettre, J.; Tazerout, M.; Rahmouni, C. Prediction of micro-explosion delay of emulsified fuel droplets. Int. J. Therm. Sci. 2009, 48, 449-460. [CrossRef]

39. Abu-Zaid, M. An experimental study of the evaporation characteristics of emulsified liquid droplets. Heat Mass Transf. 2004, 40, 737-741. [CrossRef]

40. Mohan, S.; Narsimhan, G. Coalescence of protein-stabilized emulsions in a high-pressure homogenizer. J. Colloid Interface Sci. 1997, 192, 1-15. [CrossRef] [PubMed]

41. Suzuki, Y.; Harada, T.; Watanabe, H.; Shoji, M.; Matsushita, Y.; Aoki, H.; Miura, T. Visualization of aggregation process of dispersed water droplets and the effect of aggregation on secondary atomization of emulsified fuel droplets. Proc. Combust. Inst. 2011, 33, 2063-2070. [CrossRef]

(C) 2018 by the authors. Licensee MDPI, Basel, Switzerland. This article is an open access article distributed under the terms and conditions of the Creative Commons Attribution (CC BY) license (http:// creativecommons.org/licenses/by/4.0/). 